\title{
Hepatitis C Virus, Diabetes and Steatosis: Clinical Evidence in Favor of a Linkage and Role of Genotypes
}

\author{
Sabine Mihm \\ Department of Gastroenterology and Endocrinology, University Medical Center Göttingen, Göttingen, Germany
}

\section{Key Words}

Hepatitis $C$ virus $\cdot$ Insulin resistance $\cdot$ Type 2 diabetes mellitus

\begin{abstract}
Infection with hepatitis C virus (HCV) primarily causes chronic liver disease with characteristic histopathologic features, including hepatic steatosis. Moreover, chronic hepatitis $C$ is also closely related to insulin resistance (IR) and an increased risk of type 2 diabetes mellitus (DM). This review summarizes the available clinical evidence for a linkage of chronic $\mathrm{HCV}$ infection and developing IR or DM that comprises (i) retroand prospective clinical studies, (ii) the excess risk of chronic hepatitis C patients to develop DM compared to hepatitis B patients, (iii) a preferential relationship of IR with HCV type-1, -2 or -4 infections, (iv) a correlation between IR, viral load and responsiveness to antiviral treatment and $(\mathrm{v})$ a decreased incidence of DM in chronic hepatitis $C$ after sustained virological response. This review further refers to the clinical evidence of a preferential relationship between hepatic steatosis and HCV type-3 infection, and that two distinct genotype-specific pathogenic mechanisms underlie steatosis in hepatitis C. In HCV type-3 infections, steatosis is related to viral load but not to metabolic factors, and, thus, is termed 'viral steatosis'. In HCV type-1, -2 or -4 infections, steatosis ap-
\end{abstract}

pears to be secondary to IR and regarded as 'metabolic steatosis'. In conclusion, multiple lines of clinical evidence support a linkage of HCV infection and both hepatic carbohydrate and lipid metabolism. The extent to which targeting the host's metabolism by drugs or by lifestyle change translates into an improvement of health or in a better response to interferon- $\alpha$ will provide further valuable insights into virus-host interactions, and is topic which is currently addressed in clinical studies.

Copyright $\odot 2010$ S. Karger AG, Basel

\section{Introduction}

An estimated 3\% of the world's population or 210 million people are currently affected by hepatitis $C$ virus (HCV) infection [1]. Infection with HCV primarily causes a chronic, mostly mild, inflammatory liver disease which does, however, hold a significant risk of developing into fibrosis and proceeding to liver cirrhosis. Further characteristic histologic alterations may include hepatic steatosis. It is now widely recognized that chronic hepatitis $\mathrm{C}$, moreover, is closely related to insulin resistance (IR) and to an increased risk of developing type 2 diabetes mellitus (DM). In view of the central role of the liver for maintaining overall energy homeostasis and for the con-

\section{KARGER}

Fax +4161306 1234

E-Mail karger@karger.ch

www.karger.com
(C) 2010 S. Karger AG, Basel

0257-2753/10/0281-0280\$26.00/0

Accessible online at:

www.karger.com/ddi
Sabine Mihm, Prof. Dr. rer. nat.

Department of Gastroenterology and Endocrinology

University Medical Center Göttingen, Robert-Koch-Strasse 40

DE-37075 Göttingen (Germany)

Tel. +49 551398 946, Fax +49 551397 855, E-Mail smihm@med.uni-goettingen.de 
version of carbohydrates into fat, it is not astonishing that infection with a hepatotropic virus might affect those pivotal liver functions, too [2]. As such, hepatitis $\mathrm{C}$ might be regarded not only as a viral disease of the liver, but also as a systemic disease that can exacerbate a number of other metabolic conditions.

\section{Clinical Evidence for a Linkage of Hepatitis C and IR}

The risk of chronic hepatitis $\mathrm{C}$ patients of developing IR or DM was addressed recently by a comprehensive meta-analysis [3]. Fourteen eligible retrospective studies which compared the risk of developing diabetes in chronic hepatitis $\mathrm{C}$ patients and noninfected controls yielded a pooled OR of 2, indicating a twofold excess DM risk with $\mathrm{HCV}$ infection. Multivariate estimates $(\mathrm{n}=7)$, which were adjusted for various confounding parameters such as ethnicity, smoking, viremia, etc. yielded a comparable overall risk of 1.7. In addition to these retrospective studies, which cannot establish a temporal relationship because of their cross-sectional nature, three long-term longitudinal studies with prospectively collected data were also available. Here, the incidence of developing DM was examined in hepatitis $C$ patients as well as in noninfected controls over several years of follow-up. Results from these prospective studies revealed, irrespective of whether adjusted or unadjusted data were considered, that antiHCV-positive individuals had a higher cumulative incidence of diabetes than anti-HCV-negative individuals, or, in other terms, that HCV conveys an approximately 1.7-fold excess DM risk. These prospective data indicate a temporal relationship between HCV infection and subsequent occurrence.

Evidence that the presence of HCV itself precedes development of diabetes rather than the liver injury it generates comes from the comparison of diabetes risk in hepatitis $\mathrm{C}$ and an $\mathrm{HCV}$-unrelated cause of liver injury, hepatitis $\mathrm{B}$. The meta-analysis of nine eligible studies yielded pooled unadjusted $(n=9)$ and adjusted $(n=3)$ ORs of 1.7 and 1.8, respectively. These data thus show that HCV conveys a significant excess diabetes risk beyond the risk that is conveyed by relative liver pathology and, thus, argue for a direct role of the virus in promoting carbohydrate dysregulation.

The relationship between $\mathrm{HCV}$ infection and glucose metabolism deregulation is even more pronounced when viral genotypes are considered. A study by Moucari et al. [4] of 600 hepatitis patients reported, by multiple logistic regression, $\mathrm{HCV}$ types 1 and 4 to be independent predic- tors of IR in nondiabetic patients among age, metabolic syndrome, significant fibrosis and severe steatosis. Among a subgroup of 145 patients without significant fibrosis or metabolic disorders, i.e. BMI $<25$, patients with IR were almost exclusively infected with type 1 or 4 ( $\mathrm{n}=$ 22), and IR was found to be positively correlated to serum viral load [4]. A similar dose-response relationship between HCV titer and the degree of IR after adjustment for age, gender and BMI could also be demonstrated in type 1 and type 2 patients from Taiwan [5]. These data further substantiate the presumption of IR being a direct viral feature predominately due to infection with HCV types 1,2 or 4 .

In line with the finding of a dose-response relationship between HCV titer and IR, and in line with the assumption that HCV predisposes to the development of glucose metabolism alterations, is the finding that successful intervention with virus replication, i.e. sustained virological response (SVR) to an antiviral therapy, was demonstrated to improve IR (HOMA-IR) and beta-cell function (HOMA-\%B) in a cohort of 89 type-1- and type-2-infected patients in contrast to a less successful therapy outcome, i.e. therapy relapse or treatment nonresponse [6].

Moreover, two recent studies, one from Europe and one from Japan, addressed the incidence of diabetes after the termination of an antiviral therapy in hepatitis $\mathrm{C}$, both of which came to comparable results $[7,8]$. In the larger one, more than 2,800 Japanese patients were prospectively followed over a period of up to 15 years [7]. The cumulative development rate of DM was determined to be $3.6 \%$ at 5 years, $8.2 \%$ at 10 years and $17 \%$ at 15 years. SVR was found to cause a two thirds reduction of development of DM in patients treated with interferon (IFN). Although the absence of cirrhosis and prediabetes, as well as younger age, are also associated with a reduction of development of DM, SVR could reduce the onset of DM even in patients who are older than 50 years and in patients with liver cirrhosis and prediabetes [7].

Taken together, the available clinical evidence for a linkage of chronic HCV infection and IR/DM development comprises the findings that carbohydrate dysregulation: is more prevalent in hepatitis $\mathrm{C}$ than in noninfected controls, has a higher incidence in hepatitis $\mathrm{C}$ than in noninfected controls, is more prevalent in hepatitis $C$ than in hepatitis $B$, is preferentially associated with HCV genotype-1, -2 and -4 infections, correlates to serum viral load, improves after successful antiviral therapy, and is less incident after successful eradication of the virus. 
This evidence, however, does not rule out that patients with DM might be more susceptible to HCV infection than nondiabetics. A study from Egypt on patients suffering from chronic renal failure in hemodialysis showed that patients with noninsulin-requiring or insulin-requiring DM had a ten-fold increased risk of $\mathrm{HCV}$ infection with a higher annual seroconversion rate (11 vs. $7 \%)$ than nondiabetic patients [9]. A higher susceptibility of type 2 diabetes patients to HCV infection might be due to impaired immune defense mechanisms in diabetic patients.

\section{Clinical Evidence for a Linkage of Hepatitis C and Steatosis}

Prevalence of hepatic steatosis in patients with chronic hepatitis C ranges from 40 to $80 \%$ [10]. After adjustment for steatogenic factors, prevalence of steatosis in chronic HCV infection is still $50 \%$ and thus significantly higher when compared to the general population (nonalcoholic fatty liver disease), chronic hepatitis B virus infection or autoimmune liver disease, amounting to $21 \%$, $18 \%$ and $16-21 \%$, respectively [11-14]. As for IR, the prevalence of steatosis in chronic HCV infection varies with viral genotype, i.e. hepatic steatosis was shown to be more frequent among patients with HCV type-3 infections [10, 15]. The largest study on this issue is that from Leandro et al. [11], who performed a meta-analysis on individual data from more than 3,000 patients from different geographic origins. This study clearly showed that HCV type-3 infection is the strongest factor that is independently associated with liver steatosis in lean, but also in overweight as well as obese patients. Moreover, the lipid phenotype observed in patients with HCV infection is different, e.g. from patients with non-alcoholic fatty liver disease who typically have increased serum levels of triglycerides, cholesterol and apolipoprotein B. In contrast, hepatitis $\mathrm{C}$ features total hypocholesterolemia and low high-density lipoprotein and low-density lipoprotein cholesterol serum levels when compared to healthy donors. In HCV type-3-infection, serum lipid levels are even lower than in HCV non-type-3 infections [16]. Thus, $\mathrm{HCV}$ type-3-related steatosis, in particular, is accompanied by hypolipoproteinemia.

HCV-related hypolipoproteinemia is suggested to have implications for viral spread. Circulating HCV has been shown very early by Thomssen et al. $[17,18]$ to be precipitable by antibodies directed against $\beta$-lipoproteins and immunoglobulins, leading to the hypothesis that cir- culating HCV might be associated with $\beta$-lipoproteins and immunoglobulins in low-density lipo-viral particles. Since the low-density lipoprotein receptor might mediate HCV entry into hepatocytes, low very-low-density lipoprotein/low-density lipoprotein plasma levels might promote viral dissemination by a less competitive inhibition of virus uptake $[19,20]$.

Analogous to HCV type-1, -2 and -4 infections where IR severity is associated to viral load, in HCV type-3 infection, but not in HCV type-1 infection, steatosis was found to be correlated to viral load [21].

Also analogous to HCV type-1, -2 and -4 infections where IR improves with IFN- $\alpha$ responsiveness, in HCV type-3 infection, steatosis has been shown to be revertible after eradication of HCV by successful anti-viral therapy $[21,22]$. It was unaltered, in contrast, in HCV type-3infected patients in whom a SVR was not achieved and in those with HCV type-1 infection, irrespective of treatment outcome.

At the same time, sustained clearance of HCV type 3 was associated with a normalization of baseline low serum cholesterol [22]. By contrast, cholesterol values remained unchanged in HCV type-3 nonresponders and in HCV type-1 patients, regardless of treatment response.

Whereas steatosis in HCV type-1, -2 or -4 infection is directly related to metabolic factors such as obesity or IR (but not to viral load), steatosis in HCV type-3 infection does not relate to metabolic factors but to viral load. These two obviously distinct genotype-specific pathogenic mechanisms which underlie steatosis in chronic hepatitis $\mathrm{C}$ have thus been termed 'metabolic' and 'viral' steatosis (fig. 1).

In conclusion, multiple lines of clinical evidence support a linkage of HCV infection and both hepatic carbohydrate and lipid metabolism. The better understanding of the pathophysiological linkage allows a more holistic and a genotype-based management of patients. Whether metabolic deregulation reacts upon hepatitis $C$ disease parameters as fibrosis progression or sensitivity to exogenous IFN- $\alpha$ might be attempted by therapeutic interventions targeting those systemic conditions.

\section{Current Interventional Approaches}

A pilot study which addressed the intervention through a change in lifestyle showed that even mild weight loss improves liver histology in chronic hepatitis C as early as 3 months after the start of a weight reduction program, despite the persistence of the virus [23]. Obe- 


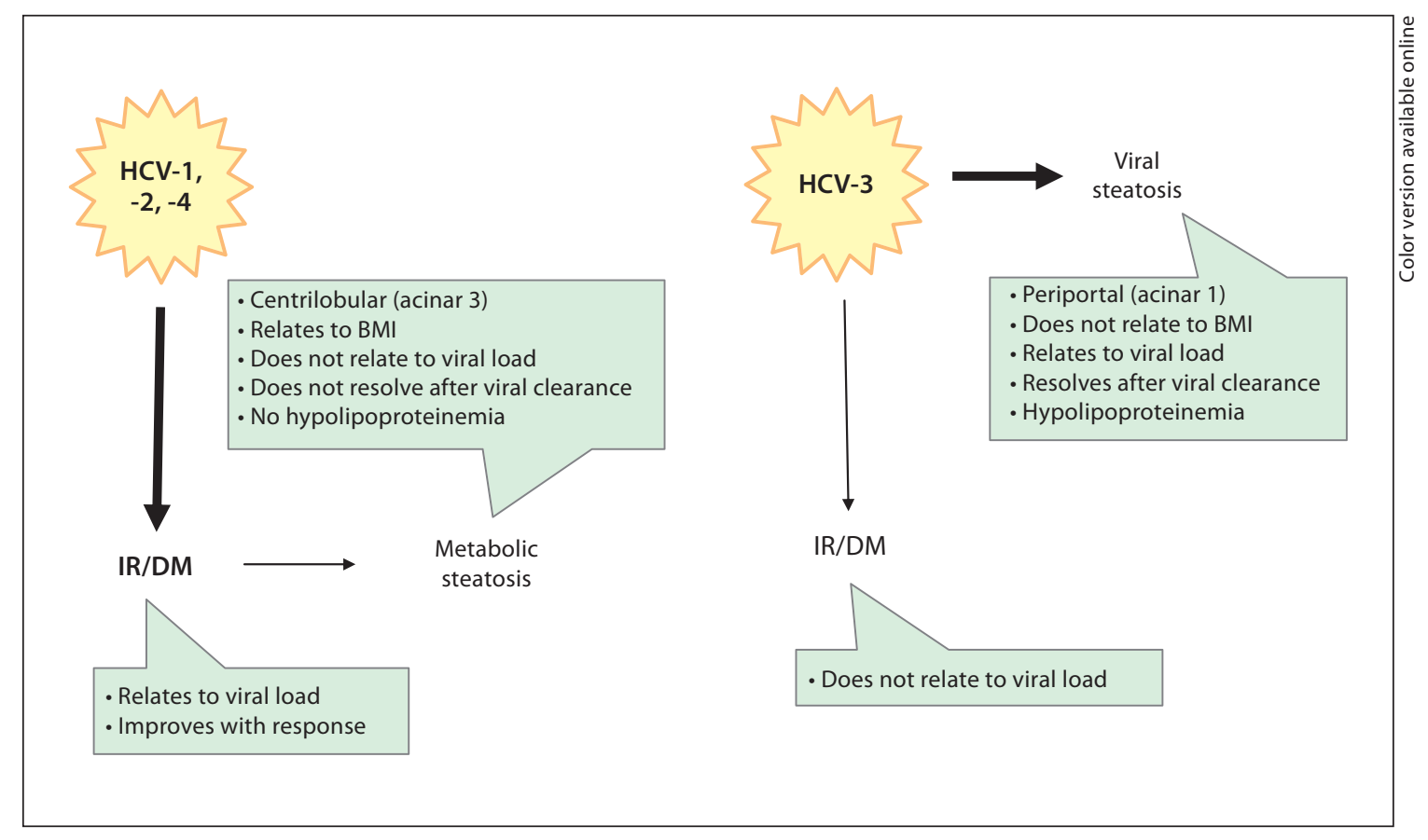

Fig. 1. Linkage between hepatitis $\mathrm{C}$, diabetes and steatosis. In chronic hepatitis C, IR/DM has been shown to be independently related to HCV type-1, -2 or -4 infection. IR/DM is associated with viral load and improves in patients who respond to an antiviral treatment. Steatosis is regarded secondary to IR/DM, thus termed 'metabolic'. It is related to metabolic factors as BMI, not to viral load, and steatosis does not resolve after viral clearance. In HCV type-3 infection, however, steatosis is the predominant feature which is related to viral load, but not to metabolic parameters. After successful antiviral treatment, steatosis resolves as hypolipoproteinemia normalizes, a condition also unique for the socalled 'viral' steatosis. sity, moreover, might also compromise antiviral treatment response due to interference with IFN- $\alpha$ bioavailability [24] or due to the pro-inflammatory state mediated by adipokines that might negatively influence anti-viral treatment response [25].

The rationale for the use of insulin sensitizers is the responsiveness to IFN- $\alpha$ and relates to the finding that IR is linked - on a molecular level - to IFN- $\alpha$ signaling [26]. Thus, improvement of IR is hypothesized to lead to an improvement of IFN- $\alpha$ sensitivity. Clinical studies on the treatment with PPAR- $\gamma$ agonists are currently under way and data are still preliminary $[27,28]$.

The rationale to use statins arises from in vitro studies showing antiviral effects of these lipid-lowering compounds. Within an organism, it was ascertained, their use might translate into an increased rate of $\mathrm{HCV}$ infection because of the competitive binding to the low-density lipoprotein receptor, as mentioned earlier, and could thus counterbalance the antiviral effects seen in vitro [29].

Hepatitis C Virus, Diabetes and Steatosis
The extent to which these approaches translate into an improvement of hepatitis $\mathrm{C}$ disease or better sensitivity to IFN- $\alpha$ might provide further valuable insights into further clinical evidence for the linkage of HCV infection and carbohydrate and lipid metabolism.

\section{Disclosure Statement}

The author declares that no financial or other conflict of interest exists in relation to the content of the article. 


\section{References}

1 Shepard CW, Finelli L, Alter MJ: Global epidemiology of hepatitis $\mathrm{C}$ virus infection. Lancet Infect Dis 2005;5:558-567.

-2 Raddatz D, Ramadori G: Carbohydrate metabolism and the liver: actual aspects from physiology and disease. Z Gastroenterol 2007;45:51-62.

-3 White DL, Ratziu V, El-Serag HB: Hepatitis $\mathrm{C}$ infection and risk of diabetes: a systematic review and meta-analysis. J Hepatol 2008;49: 831-844.

-4 Moucari R, Asselah T, Cazals-Hatem D, Voitot H, Boyer N, Ripault MP, Sobesky R, Martinot-Peignoux M, Maylin S, Nicolas-Chanoine $\mathrm{MH}$, Paradis V, Vidaud M, Valla D, Bedossa P, Marcellin P: Insulin resistance in chronic hepatitis C: association with genotypes 1 and 4, serum HCV RNA level, and liver fibrosis. Gastroenterology 2008; 134 : 416-423.

5 Hsu CS, Liu CJ, Liu CH, Wang CC, Chen CL, Lai MY, Chen PJ, Kao JH, Chen DS: High hepatitis $\mathrm{C}$ viral load is associated with insulin resistance in patients with chronic hepatitis C. Liver Int 2008;28:271-277.

-6 Kawaguchi T, Ide T, Taniguchi E, Hirano E, Itou M, Sumie S, Nagao Y, Yanagimoto C, Hanada S, Koga H, Sata M: Clearance of $\mathrm{HCV}$ improves insulin resistance, beta-cell function, and hepatic expression of insulin receptor substrate 1 and 2. Am J Gastroenterol 2007;102:570-576.

7 Arase Y, Suzuki F, Suzuki Y, Akuta N, Kobayashi M, Kawamura Y, Yatsuji H, Sezaki H, Hosaka T, Hirakawa M, Ikeda K, Kumada H: Sustained virological response reduces incidence of onset of type 2 diabetes in chronic hepatitis C. Hepatology 2009;49:739-744.

-8 Romero-Gomez M, Fernandez-Rodriguez CM, Andrade RJ, Diago M, Alonso S, Planas R, Sola R, Pons JA, Salmeron J, Barcena R, Perez R, Carmona I, Duran S: Effect of sustained virological response to treatment on the incidence of abnormal glucose values in chronic hepatitis C. J Hepatol 2008;48:721727.

-9 Saxena AK, Panhotra BR: The susceptibility of patients with type-2 diabetes to hepatitis $\mathrm{C}$ virus infection during long-term haemodialysis. Swiss Med Wkly 2003;133:611-618.
10 Machado MV, Cortez-Pinto H: Insulin resistance and steatosis in chronic hepatitis $\mathrm{C}$. Ann Hepatol 2009;8(suppl 1):S67-S75.

- 11 Leandro G, Mangia A, Hui J, Fabris P, Rubbia-Brandt L, Colloredo G, Adinolfi LE, Asselah T, Jonsson JR, Smedile A, Terrault N, Pazienza V, Giordani MT, Giostra E, Sonzogni A, Ruggiero G, Marcellin P, Powell EE, George J, Negro F: Relationship between steatosis, inflammation, and fibrosis in chronic hepatitis C: a meta-analysis of individual patient data. Gastroenterology 2006;130:16361642 .

12 Clark JM, Brancati FL, Diehl AM: Nonalcoholic fatty liver disease. Gastroenterology 2002;122:1649-1657.

13 Thomopoulos KC, Arvaniti V, Tsamantas AC, Dimitropoulou D, Gogos CA, Siagris D, Theocharis GJ, Labropoulou-Karatza C: Prevalence of liver steatosis in patients with chronic hepatitis B: a study of associated factors and of relationship with fibrosis. Eur J Gastroenterol Hepatol 2006;18:233-237.

14 Bach N, Thung SN, Schaffner F: The histological features of chronic hepatitis $\mathrm{C}$ and autoimmune chronic hepatitis: a comparative analysis. Hepatology 1992;15:572-577.

15 Mihm S, Fayyazi A, Hartmann H, Ramadori G: Analysis of histopathological manifestations of chronic hepatitis $\mathrm{C}$ virus infection with respect to virus genotype. Hepatology 1997;25:735-739.

16 Negro F, Sanyal AJ: Hepatitis C virus, steatosis and lipid abnormalities: clinical and pathogenic data. Liver Int 2009;29(suppl 2): 26-37.

17 Thomssen R, Bonk S, Thiele A: Density heterogeneities of hepatitis $C$ virus in human sera due to the binding of beta-lipoproteins and immunoglobulins. Med Microbiol Immunol 1993;182:329-334.

18 Thomssen R, Bonk S, Propfe C, Heermann KH, Kochel HG, Uy A: Association of hepatitis $\mathrm{C}$ virus in human sera with beta-lipoprotein. Med Microbiol Immunol 1992;181 293-300.

19 Monazahian M, Bohme I, Bonk S, Koch A, Scholz C, Grethe S, Thomssen R: Low density lipoprotein receptor as a candidate receptor for hepatitis C virus. J Med Virol 1999; 57:223-229.
20 Agnello V, Abel G, Elfahal M, Knight GB, Zhang QX: Hepatitis C virus and other flaviviridae viruses enter cells via low density lipoprotein receptor. Proc Natl Acad Sci USA 1999;96:12766-12771.

-21 Poynard T, Ratziu V, McHutchison J, Manns M, Goodman Z, Zeuzem S, Younossi Z, Albrecht J: Effect of treatment with peginterferon or interferon alfa- $2 \mathrm{~b}$ and ribavirin on steatosis in patients infected with hepatitis C. Hepatology 2003;38:75-85.

-22 Kumar D, Farrell GC, Fung C, George J: Hepatitis $C$ virus genotype 3 is cytopathic to hepatocytes: reversal of hepatic steatosis after sustained therapeutic response. Hepatology 2002;36:1266-1272.

23 Hickman IJ, Clouston AD, Macdonald GA, Purdie DM, Prins JB, Ash S, Jonsson JR, Powell EE: Effect of weight reduction on liver histology and biochemistry in patients with chronic hepatitis C. Gut 2002;51:89-94.

24 Charlton MR, Pockros PJ, Harrison SA: Impact of obesity on treatment of chronic hepatitis C. Hepatology 2006;43:1177-1186.

-25 Jonsson JR, Barrie HD, O'Rourke P, Clouston AD, Powell EE: Obesity and steatosis influence serum and hepatic inflammatory markers in chronic hepatitis C. Hepatology 2008;48:80-87.

-26 Pazienza V, Clement S, Pugnale P, Conzelman S, Foti M, Mangia A, Negro F: The hepatitis $\mathrm{C}$ virus core protein of genotypes $3 \mathrm{a}$ and $1 \mathrm{~b}$ downregulates insulin receptor substrate 1 through genotype-specific mechanisms. Hepatology 2007;45:1164-1171.

27 Overbeck K, Genne D, Golay A, Negro F: Pioglitazone in chronic hepatitis $\mathrm{C}$ not responding to pegylated interferon-alpha and ribavirin. J Hepatol 2008;49:295-298.

-28 Serfaty L, Fartoux L, Poupon R: Pioglitazone as adjuvant therapy in chronic hepatitis $\mathrm{C}$ : sequential rather than concomitant administration with pegylated interferon and ribavirin? J Hepatol 2009;50:1269-1271.

-29 Lonardo A, Loria P, Bertolotti M, Carulli N: Statins and HCV: a complex issue. Hepatology 2007; $45: 257$ 